\title{
CBERS 3\&4 TM Thermal Balance Test Results and Satellite Thermal Mathematical Model Correlation
}

\author{
Rosângela Meireles Gomes Leite and Li Guoqiang \\ Instituto Nacional de Pesquisas Espaciais, São José dos Campos, Brazil, 12227-010 and Chinese Academy of \\ Spacecraft Technology, Beijing, China, 100094 \\ Valeri Vlassov, Geng Liyin \\ Instituto Nacional de Pesquisas Espaciais, São José dos Campos, Brazil, 12227-010 and Chinese Academy of \\ Spacecraft Technology, Beijing, China, 10009 \\ and \\ Gustavo Adolfo Ronceros Rivas, Chen Entao and Wang Bin \\ Instituto Nacional de Pesquisas Espaciais, São José dos Campos, Brazil, 12227-010 and Chinese Academy of \\ Spacecraft Technology, Beijing, China, 100094
}

\begin{abstract}
CBERS 3\&4, China-Brazil Earth Resource Satellites, projected for 3 years of remote sensing mission in Sun Synchronous orbit, are at the present under development. Brief description of satellites is given. On September of 2009 the thermal balance test (TBT) of the full-scale thermal model (TM) of the satellite CBERS3\&4 was performed. During the TBT, seven modes of satellite operation were reproduced; they include cold and hot steady-state and transient cases, surviving and specific modes of operation. Analysis of obtained data has demonstrated the thermal design is qualified. In this paper the main results of TBT are presented. TM layout, TBT configuration and phases simulated are given. Two thermal mathematical models (TMM) were used in parallel for the satellite thermal design validation by the test results; their descriptions, main results of simulation and correlation are presented. Lessons learned include observations on the TBT campaign as well as for TMM features and correlations are also included.
\end{abstract}

\section{Nomenclature}

$\begin{array}{ll}\text { CAST } & =\text { Chinese Academy of Space Technology } \\ C B E R S & =\text { China-Brazil Earth Resources Satellite } \\ C C D & =\text { charge coupled device } \\ G P S & =\text { global positioning system } \\ H R C & =\text { high resolution camera } \\ I D S & =\text { interface data sheet } \\ I N P E & =\text { National Institute for Space Research } \\ I R A & =\text { infrared array } \\ I R M S S & =\text { infrared multispectral scanner } \\ I R S C a m & =\text { infrared scanner camera } \\ \text { LIT } & =\text { Laboratory of Integration and Test } \\ \text { MUXcam } & =\text { multispectral camera } \\ \text { OSR } & =\text { optical solar reflector } \\ P A N c a m & =\text { panchromatic multispectral camera } \\ P M & =\text { payload module } \\ S M & =\text { service module } \\ T B T & =\text { thermal balance test } \\ T C S S & =\text { thermal control subsystem } \\ T M & =\text { thermal model }\end{array}$

American Institute of Aeronautics and Astronautics 
$\begin{array}{ll}T M M & =\text { thermal mathematical model } \\ T V C & =\text { thermal vacuum chamber } \\ W F I & =\text { wide field imaging camera }\end{array}$

\section{Introduction}

$\mathrm{T}$ he China-Brazilian Earth Resources Satellite (CBERS) program, the result of a space technology agreement between China and Brazil, was officially signed in 1988 after the first joint work report produced by National Institute for Space Research (INPE) and the Chinese Academy of Space Technology (CAST). This report presented the master plan for the joint development of first satellite of the CBERS series based on the systems approach used in the Chinese Earth Resources Satellite ZY-1. The financial investment foreseen for the program was divided between both countries as follows: CAST was responsible for $70 \%$ and INPE for $30 \%$ of the total cost, which included the costs of the satellite development (including the flight models), the acquisition of two launch vehicles and launch services, to be provided by the Chinese side. [ref. de Oliveira].

During the 20 years of its existence, the program of cooperation between China and Brazil in space has achieved the successful launch of three satellites, and new launches are expected in the next years. It has become an unique example of cooperation in cutting edge technology between emerging nations; has involved (and continues to involve) Brazilian industry in the fabrication of the satellites, and has originated a policy of universal and free distribution of satellite images, benefiting today the countries of Latin America and Africa. [ref. de Oliveira]

The CBERS-1 and CBERS-2 satellites were successfully launched on October 14, 1999, and on Oct.21, 2003 aboard the Long March 4B rocket, from the Taiyuan Launch Center in China.

The instruments aboard the first two CBERS satellites are the CCD Camera, the Wide Field Imager- WFI and the Infrared Multispectral Scanner (IRMSS). The CCD is a charge coupled device instrument with 20 meters ground resolution and 5 spectral bands ranging from blue to near infrared. The WFI is an array detector device with 250 meters ground resolution and 2 bands centered in the red and the infrared channels. The IRMSS is a traditional scanner with 80 meters resolution in the PAN and the SWIR bands and 160 meters in the thermal band. The polar orbiting platform supports two channels to transfer data at 53 megabits/second. This configuration allows CBERS to transfer the data simultaneously to Brazil and to other receiving station that operates in X band. [ref. Martini]

Owing to the success of CBERS-1 and 2, the two governments decided, in November 2002, to give continuity to the CBERS program by signing a new agreement for the development and launch of two more satellites, CBERS$3 \& 4$. In this project the Brazilian participation was increased to 50\%, putting Brazil on an equal footing with the Chinese. CBERS-3 was expected to be launched in 2009, CBERS-4 in 2011. [ref. www.cbers.inpe.br]

On June 14, 2004, the Brazilian Government announced that free internet access to the entire catalog of CBERS2 images would be granted to the Brazilian people. On November, 2004, China and Brazil signed a complementary protocol, this time dealing with distribution of CBERS products to other countries. [ref. de Oliveira]

At this time, the launch of CBERS-3 was set for 2008. As the useful life of CBERS-2 was estimated to be 2 years, i.e. until 2005, the two countries agreed on the need to cover the gap that would be left between the end of CBERS-2 and the entry into operation of CBERS-3. It was necessary to guarantee the supply of data from the satellites. For this reason the decision to construct the satellite. CBERS-2B with launch set for 2006 was confirmed in a new document. [ref. de Oliveira]

CBERS-2B, still belonging to the first CBERS satellite generation is therefore almost identical to CBERS-1 and 2. However, some improvements were adopted. The main one concerns the payload, with the replacement of the IRMSS imager by a High-Resolution Panchromatic Camera (HRC). Additional improvements are a new on-board recording system, and an advanced positioning system, which includes GPS (Global Positioning System) and star sensors. [ref. www.cbers.inpe.br]

CBERS-2B was an alternative of low cost since it has been built with equipment and remaining parts of the CBERS-2, produced in duplicate for questions of security and contingency. The CBERS-2B was successfully launched on September 19, 2007 aboard the Long March 4B rocket, from the Taiyuan Launch Center in China after a very short schedule of development that demanded an enormous responsibility of the both expert teams and involved so many risks.

In the work sharing of the CBERS program CAST is responsible for the TCSS and INPE has the responsibility for accompanying all the development of the satellite thermal design and tests. Both countries have developed their own satellite TMM. Some critical thermal issues, like evaluation of battery temperatures, layout of equipment, radiation areas and heater powers were resolved in cooperation with the INPE thermal group. 
The main objectives of the thermal balance test (TBT) on the satellite thermal model (TM) are: to verify the adequacy of the satellite thermal design in the simulated worst case on-orbit hot and cold environmental and operational conditions [ref. Krein], to determine experimentally estimated thermal properties of the TCSS, such as, thermal resistances at interfaces, MLI and panel effective conductance, etc, to provide experimental test data to verify/validate/modify the satellite thermal mathematical model, to identify in advance possible problem areas. [ref. Sacchi].

\section{CBERS 3\&4 mission and satellite description}

CBERS-3\&4 are an evolution of the CBERS $1 \& 2$ satellites, projected for 3 years mission. They will use 4 camera payload modules (PANcam - Panchromatic Multispectral camera- MUXcam, medium resolution sweep camera - IRScam and Wide Field imaging camera - WFIcam) with improved geometric and radiometric performance. The orbit of two satellites will be same as for CBERS-1\&2. [ref. de Oliveira]

The satellites are designed to acquire and operate in a sun synchronous, recurrent and frozen orbit with the following nominal parameters: semi-major axis (average) 7148.865 $\mathrm{km}$, inclination $98.504 \mathrm{deg}$, eccentricity $1.1 \mathrm{x}$ $10-3$, eccentricity error $<0.0001$, argument of perigee $90 \mathrm{deg}$, argument of perigee error $<5$ deg, local time at descending node 10:30 a.m., orbital period $100.26 \mathrm{~min}$, repeat cycle 26 days, revolution/day $14+9 / 26$, inter-track distance at equator line $106.25 \mathrm{~km}$, time interval between adjacent tracks 3 days, orbit trace stability at the

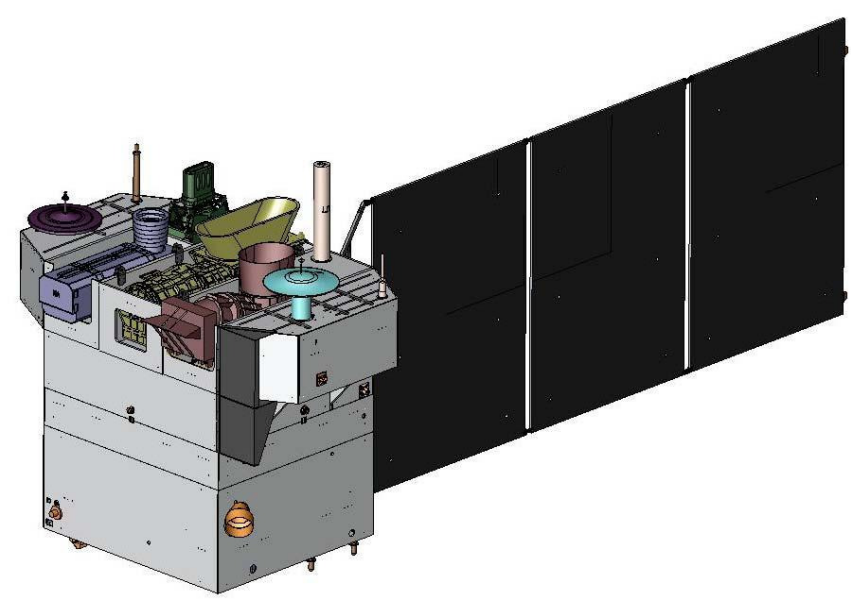

Figure 1. CBERS 3\&4 satellites schematic view. equator $+5 \mathrm{~km}$.

\section{Thermal project}

Due to the positive technical results confirmed through Thermal Control Subsystem (TCSS) temperatures telemetries in orbit, that consequently have contributed and guaranteed the good satellite performance during the other preceding CBERS missions, it was decided to adopt CBERS-3\&4 thermal design as heritage of CBERS-1\&2.

For CBERS-1\&2, the basic idea of TCSS is to design the Payload (PM) and Service Module (SM) separately and keep them insulated thermally. The TCSS uses primarily passive control techniques mainly and only uses active control where necessary.

Thus the thermal control of the CBERS-3, based on CBERS-1\&2 thermal approach, will be accomplished mainly using passive but also active thermal (wherever necessary) control elements.

There are proper radiators on some external surfaces of side panels (Fig. 2). For Sun-facing side of PM and SM and bottom side of SM, OSR of quartz glass is used. To other sides, for example, $+\mathrm{Y}$ and $+\mathrm{Z}$ sides, $\mathrm{S} 781$ white paint is applied. The other regions that are not radiator areas are completely covered by MLI blankets. All internal surfaces of side walls and external surfaces of electronic equipment boxes are painted to improve internal radiation heat transfer.. Aluminum-ammonia grooved heat pipes with high heat transfer efficient are embedded into honeycomb panels and also installed externally on some walls where high and variable heat dissipation devices such as TWT, TWT power supplies, SSPA, shunt and BDR, and so on, are located. For those constant work instruments with large dissipation, thermal grease or indium sheets are used at the interfaces between instrument baseplates and mounting panels to minimize the contact resistance. 
Due to lower limit of temperature specified for the Propulsion components as $+5^{\circ} \mathrm{C}$, and as these components are not dissipative and are widely positioned in the satellite, the hydrazine tanks and their pipelines, control valves and thrusters are controlled actively by electrical heaters.

Eight (8) heating circuits are designed to control the satellite propulsion components by Onboard Data Handling Subsystem $(\mathrm{OBDH})$ that sends the open and close commands to the circuits of heating. MLI is used to cover the external surfaces of these components to keep their temperatures in the specified range.

MLI and electrical heaters are also used to control temperatures of $\mathrm{Ni}-\mathrm{Cd}$ battery packs, whose heat dissipations are radiated to space through their mounting panel with an OSR radiator. To reduce the temperature difference between each battery packs of the same battery, circular heat pipes were inserted into the battery mounting panel.

In order to satisfy the strict temperature control requirements for cameras, appropriate heat isolating measures are adopted between cameras and satellite structure.

\section{Thermal control verification and TBT plan}

The strategy adopted for the TCSS and Thermal Architecture verification was to perform the satellite thermal analysis, separately for PM and SM in the preliminary phase of the design, before TBT.

To accomplish the TBT for the whole satellite, including the Service Model (SM), taking into account that, as already shown in Section III, the changes introduced in the SM, in spite of the CBERS 1\&2 heritage were significant. Especially for the $\mathrm{Ni}-\mathrm{Cd}$ batteries with narrow range of temperature and heat dissipations very large at the satellite end of life, which

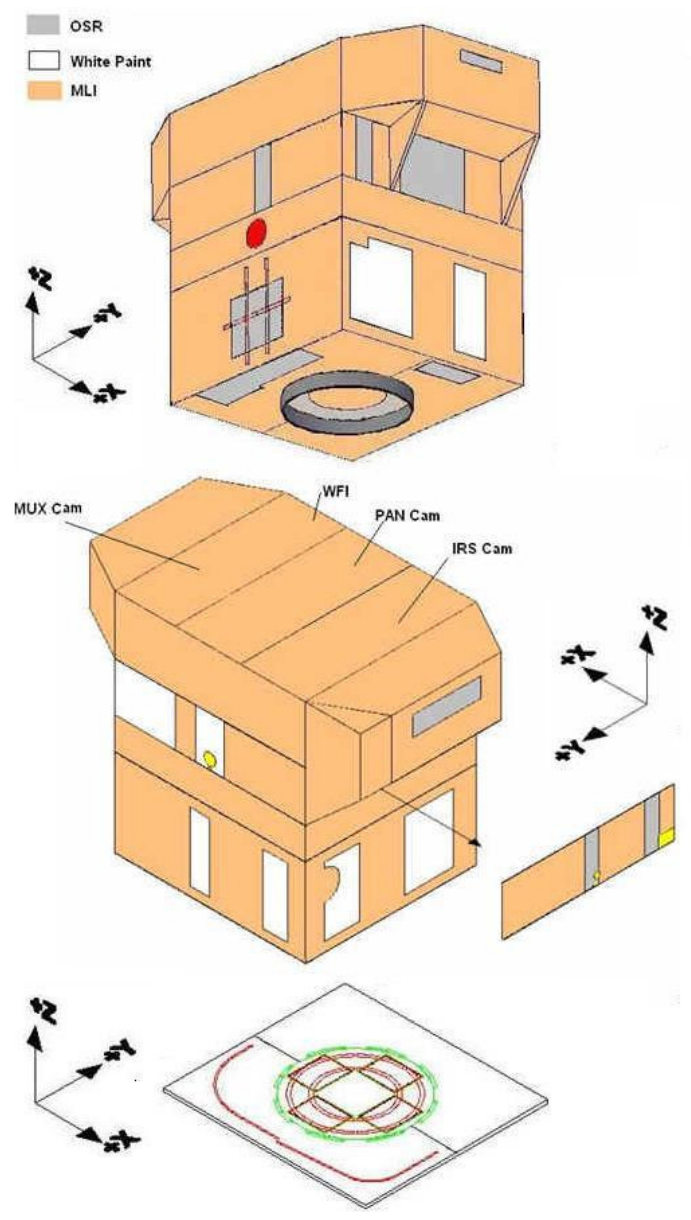

Figure 2. CBERS 3\&4 TM thermal configuration. were transferred from Face Y+, satellite shadowed face, to Face Z-, face that during the satellite survival condition, is kept directed to the Sun.

To conclude the TCSS and Thermal Architecture verification process, after the verification of the satellite thermal design and adjustment of the satellite TMM (model considering both satellite modules already integrated) with the TBT results, the validation of the Thermal Control was done with the temperature prediction for the satellite flight model (FM).

During TBT, 7 modes of satellite operation were reproduced; they include cold and hot steady-state (4 cases), transient cases (3 cases), surviving and specific modes of observation.

\section{TM test configuration and non-conformances}

The test was conducted in $6 \times 8 \mathrm{~m}$ thermal vacuum chamber (TVC) of the Laboratory of Integration and Test. (LIT) at INPE during 14 days. There were 468 thermocouples type $\mathrm{T}(\mathrm{Cu}-\mathrm{Cn})$ installed on the TM, including 46 used on IRSCam. Skin heaters installed on the external surfaces (MLI and radiators) of the satellite

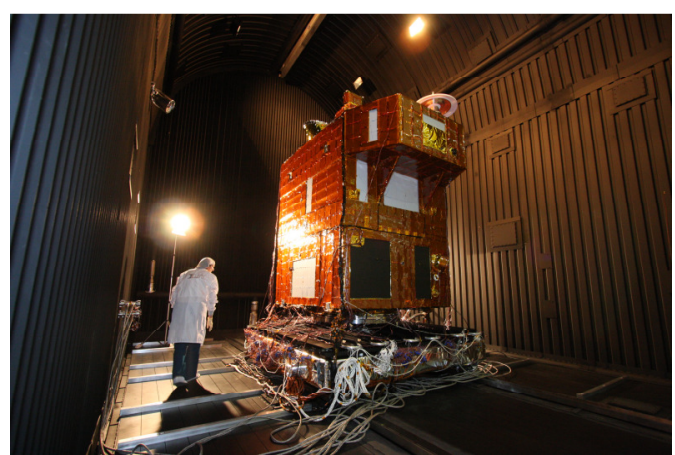

Figure 3. CBERS-3 TM inside TVC.

simulated the absorbed heat fluxes by the satellite in each case of the test (Fig. 3). An infrared array (IRA) with electrical heaters, type calrods, simulated the heat fluxes on the IRSCam (Fig.4). The IRA was installed in a dedicated support which was thermally insulated from the satellite. Skin heaters are also used to simulate the equipment dummy heat dissipations. During test, the current error of each circuit was smaller than $10 \mathrm{~mA}$ and the 
resistance error of each skin heater circuit was smaller than $0.1 \Omega$. Therefore, errors of external fluxes and dummy heat dissipations simulated by skin heater were neglected.

The satellite was installed on a support (loading cart) on the bottom of the TVC. The cart was connected with the inferior flange of the satellite central cylinder. To provide a representative thermal shroud configuration and corresponding temperature sink to the satellite Face $\mathrm{Z}^{-}$, which included the battery radiators, LIT developed an important and dedicated cold plate on the satellite loading cart providing a near $100 \%$ viewfactor from this satellite face to the effective heat sink (Fig. 5).

A thermal interface was also developed to control the temperature between the support and the satellite, to prevent heat leak from the satellite to the interface using temperature control software, to impose in the thermal interface the same temperature that the satellite reached in the contact region (Fig. 5). During test the difference between TM support average temperature and the support average temperature was smaller than $0.6^{\circ} \mathrm{C}$.

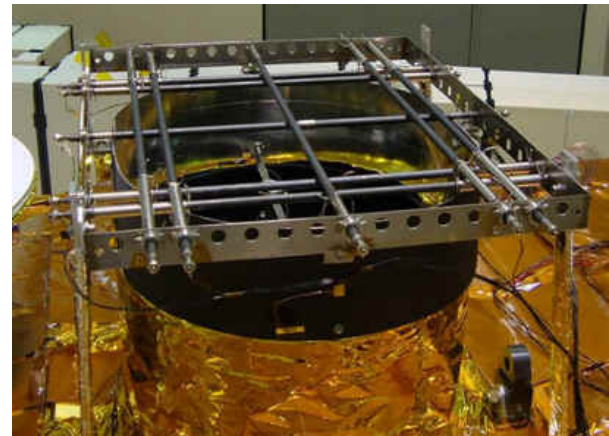

Figure 4. IRA over the IRSCam window.

Fourteen (14) radiometers were installed on all surfaces that receive the heat fluxes simulated by the IRA and satellite surfaces that receive background heat flux (2 radiometers on each side of the TM).

During TBT, the IRA and the radiometers worked normally. However, the cold plate did not comply with the TBT specification requirements in value of temperature and uniformity $\left(-180^{\circ} \mathrm{C} \pm 3^{\circ} \mathrm{C}\right)$. This has generated a non-conformance during the test. During the cold cases the cold plate temperatures were kept from $-98^{\circ} \mathrm{C}$ to $-156^{\circ} \mathrm{C}$ on the region directly under the battery radiators and in the range of $-78^{\circ} \mathrm{C}$ to $-140^{\circ} \mathrm{C}$ during the TBT hot cases, influencing the battery temperatures and the lower part of the satellite. To overcome this problem during all cases of the test, the background heat flux on satellite Face $\mathrm{Z}$, measured by the radiometer installed on the battery panel, was

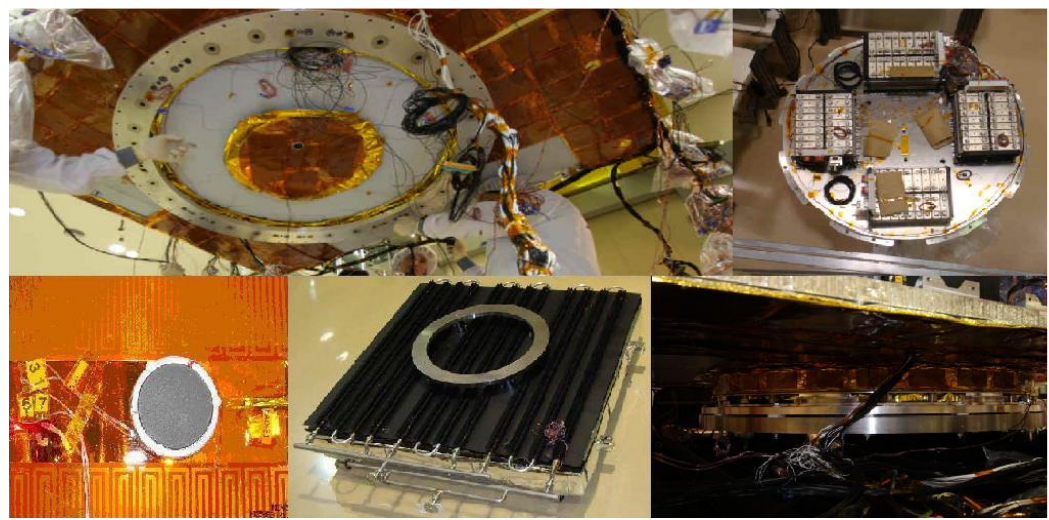

Figure 5. Battery panel radiometer and cold plate, radiometer detail, satellite and support interface, battery panel discounted from the fluxes to be simulated on the Face $Z^{-}$radiators. These background heat fluxes were in the range of $17 \sim 45 \mathrm{~W} / \mathrm{m}^{2}$.

Another non-conformance was related to problems experienced with the acquisition data software, when 2 electrical power supplies stopped working during the last case of the TBT (the battery heater control and the WFI MLI heater control were turned OFF during 40 minutes and 11 minutes, respectively). The effects of these 2 nonconformances were eliminated during test. For the first one, at the time of acquisition system error, the battery temperature had been in convergence. For WFI MLI, the OFF time of heater was short and there was no impact on temperature convergence.

\section{Test main results}

Before TM TBT, the SM and PM thermal mathematical models were built to predict the temperature of test cases. After test, TMM results and test results were compared according to the 2 steady states (Cold Case 1 and Hot Case 5), whose results measured in TBT are presented in Table 1 for the satellite equipment. Summarily, the main results were as following.

Cold cases 1,2 and Phase 2a (to simulate the extreme cold steady and transient cases): all of the SM equipment were in the range of $3^{\circ} \mathrm{C}$ to $25^{\circ} \mathrm{C}$, except for the Infrared Earth Sensor-A (IRES-A) with $27^{\circ} \mathrm{C}$ due to its active thermal control, the Bearing and Power Transfer Assembly (BAPTA) that was $38^{\circ} \mathrm{C}$. The 4 Battery Pack temperatures were in the range of $4.26^{\circ} \mathrm{C}$ to $4.99^{\circ} \mathrm{C}$, and the temperature difference between 2 packs of one same battery was less than $0.8^{\circ} \mathrm{C}$, much less than the $5^{\circ} \mathrm{C}$ requirement. In the transient (Case 2) the 4 battery temperatures were in the range of $3.3^{\circ} \mathrm{C}$ to $4.3^{\circ} \mathrm{C}$ and the temperature difference between each two pack was less than $0.6^{\circ} \mathrm{C}$. For 
$\mathrm{PM}$, all the equipment temperatures were in the range of $1{ }^{\circ} \mathrm{C}$ to $13^{\circ} \mathrm{C}$, except for the equipment of the MUXcam \& WFI Transmission Subsystem, whose range was $-11^{\circ} \mathrm{C}$ to $0.6^{\circ} \mathrm{C}$, since they were OFF, and equipment in PM20 in the lower center region of $\mathrm{PM}$ were in the range of $19^{\circ} \mathrm{C}$ to $23^{\circ} \mathrm{C}$.

Hot cases 5, 6,7 and Phase 5a (to simulate the extreme hot steady-state and transient cases):

In Case 5, according to the test results, all of the SM equipment were in the range $15^{\circ} \mathrm{C}$ to $36^{\circ} \mathrm{C}$, except for the BAPTA whose temperature was $50.7^{\circ} \mathrm{C}$ due to its internal heat dissipation being higherthan expected. The 4 Battery Pack temperatures were in the range of $5.9^{\circ} \mathrm{C}$ to $6.2^{\circ} \mathrm{C}$ and the temperature difference between 2 packs was less than $0.3^{\circ} \mathrm{C}$. For PM, all the equipment temperature is at the range of $17^{\circ} \mathrm{C}$ to $26^{\circ} \mathrm{C}$, except for MWT equipment $\left(11^{\circ} \mathrm{C}\right.$ to $\left.20^{\circ} \mathrm{C}\right)$ and the equipment installed in the PM front panel, PM lower center region $\left(33^{\circ} \mathrm{C}\right.$ to $\left.34^{\circ} \mathrm{C}\right)$.

In Case 6, before this case starts the heat dissipations of some equipment (BDR, Shunt, BCHC) installed in the SM were updated to the flight model (FM) IDS values, which are quite different from the values specified for the TM. The average heat dissipations these equipment in one orbit were much smaller than values used in Case 5. The differences were $13.2 \mathrm{~W}, 40.8 \mathrm{~W}$ and $10.5 \mathrm{~W}(64.5 \mathrm{~W}$ smaller than in values used in Case 5). So, the temperatures obtained for the equipment of SM6 were about $15^{\circ} \mathrm{C}$ colder in relation to Case 5 results. The temperatures in SM6 neighbor compartments also decreased $8^{\circ} \mathrm{C}$ to $10^{\circ} \mathrm{C}$. All SM equipment were in the range of $7^{\circ} \mathrm{C}$ to $34^{\circ} \mathrm{C}$, except for the BAPTA that was at the level of $36^{\circ} \mathrm{C}$ to $41^{\circ} \mathrm{C}$, results already based on the new heat dissipation (in flight mode). The 4 Battery Pack temperatures were in the range of $4.5^{\circ} \mathrm{C}$ to $6.1^{\circ} \mathrm{C}$, and the temperature difference of between 2 packs was less than $0.4^{\circ} \mathrm{C}$. The PM equipment temperatures are higher than Case 5. In Case 6, the satellite worked 8 orbits in one day, one more orbit

Table 1. TM TBT results - cold and hot steady state cases

\begin{tabular}{|c|c|c|c|c|c|c|c|c|c|c|c|c|c|}
\hline \multicolumn{6}{|c|}{ PM } & & \multicolumn{7}{|c|}{ SM } \\
\hline \multirow{2}{*}{$\begin{array}{c}\text { Equipment } \\
\text { codes }\end{array}$} & \multicolumn{3}{|c|}{ Case 1 - cold case } & \multicolumn{3}{|c|}{ Case 5-hot case } & \multirow{2}{*}{$\begin{array}{l}\text { Equipment } \\
\text { codes }\end{array}$} & \multicolumn{3}{|c|}{ Case 1 - cold case } & & se 5 - hot ca & \\
\hline & TMM & \begin{tabular}{|l|} 
TBT \\
\end{tabular} & \begin{tabular}{|l|l} 
Diff \\
\end{tabular} & \begin{tabular}{|l|} 
Model \\
\end{tabular} & \begin{tabular}{|l|} 
TBT \\
\end{tabular} & \begin{tabular}{|l|} 
Diff \\
\end{tabular} & & \begin{tabular}{|l|} 
TMMM \\
\end{tabular} & TBT & \begin{tabular}{|l|} 
Diff. \\
\end{tabular} & Model & TBT & Diff \\
\hline RBJA & -0.21 & 6.51 & \begin{tabular}{|l|l|}
6.72 \\
\end{tabular} & \begin{tabular}{|l|}
27.19 \\
\end{tabular} & 23.36 & -3.83 & RBCJ & 6.44 & 7.42 & \begin{tabular}{|l|}
0.98 \\
\end{tabular} & 20.28 & 19.42 & -0.86 \\
\hline RBIS & -5.80 & 2.99 & 8.79 & \begin{tabular}{|l|}
21.51 \\
\end{tabular} & 20.32 & -1.19 & RBC4 & \begin{tabular}{|l|}
24.33 \\
\end{tabular} & 24.59 & \begin{tabular}{|l|}
0.26 \\
\end{tabular} & \begin{tabular}{|l|}
34.79 \\
\end{tabular} & 33.78 & $\mid-1.01$ \\
\hline REHH-C & -2.66 & 4.46 & 7.12 & 25.51 & 22.18 & -3.33 & RBCF & 18.59 & 21.11 & 2.52 & 29.72 & 31.16 & 1.44 \\
\hline REHH-A & 0.21 & 5.64 & 5.43 & 29.25 & 23.78 & -5.47 & $\mathrm{RECH}$ & 15.05 & 17.69 & \begin{tabular}{|l|}
2.64 \\
\end{tabular} & 26.55 & 27.22 & 0.67 \\
\hline RENH-B & -0.83 & 4.99 & 5.82 & 27.29 & 23.09 & -4.20 & RECG & \begin{tabular}{|l|}
9.38 \\
\end{tabular} & 8.49 & \begin{tabular}{|l|}
-0.89 \\
\end{tabular} & 26.16 & 26.50 & 0.34 \\
\hline RBJG-A & -2.33 & 4.52 & 6.85 & 26.51 & 22.92 & -3.59 & $\mathrm{REC3}$ & 25.38 & 22.74 & -2.64 & 31.46 & $27.05 / 22.01$ & \begin{tabular}{|l|l|}
-4.41 \\
\end{tabular} \\
\hline REJG-C & -2.62 & 4.15 & 6.77 & 25.62 & 22.19 & -3.43 & RBC3 & 29.41 & 36.48 & 7.07 & \begin{tabular}{|l|}
34.14 \\
\end{tabular} & 35.7 & 1.56 \\
\hline REJG-B & -1.92 & 4.36 & \begin{tabular}{|l|l|}
6.28 \\
\end{tabular} & 26.83 & 22.7 & \begin{tabular}{|l|l|}
-4.13 \\
\end{tabular} & RBCS-A-Box & 17.17 & 14.59 & \begin{tabular}{|l|}
-58 \\
\end{tabular} & 27.65 & 25.10 & -2.55 \\
\hline REJJ-A & -3.74 & 4.13 & \begin{tabular}{|l|}
7.87 \\
\end{tabular} & \begin{tabular}{|l|}
23.97 \\
\end{tabular} & 21.77 & \begin{tabular}{|l|}
-2.20 \\
\end{tabular} & RBCS-A-Box & 5.55 & 0.77 & \begin{tabular}{|l|}
-4.78 \\
\end{tabular} & 11.63 & 9.60 & -2.03 \\
\hline REJJ-B & -4.11 & 3.5 & 7.61 & \begin{tabular}{|l|}
23.44 \\
\end{tabular} & 21.03 & $\mid-2.41$ & RECE-B & 13.06 & 17.35 & 4.29 & 28.65 & 25.69 & -2.96 \\
\hline RERR & -4.41 & \begin{tabular}{|l|}
2.4 \\
\end{tabular} & 6.81 & 22.95 & 19.61 & -3.34 & RBCE-A & 14.20 & 27.07 & 12.87 & \begin{tabular}{|l|}
26.42 \\
\end{tabular} & 27.39 & 0.97 \\
\hline RBKK & -3.34 & 4.98 & 8.32 & 25.81 & 23.26 & -2.55 & RBDF & \begin{tabular}{|l|}
14.71 \\
\end{tabular} & 16.29 & 1.58 & \begin{tabular}{|l|}
24.74 \\
\end{tabular} & 23.83 & $\mid-0.91$ \\
\hline REJB & -5.42 & 1.95 & 7.37 & \begin{tabular}{|l|}
20.71 \\
\end{tabular} & 18.98 & -1.73 & REFB-B & 18.34 & 22.29 & 3.95 & 28.38 & 30.64 & 2.26 \\
\hline $\mathrm{RBJC}$ & -0.66 & 5.82 & 6.48 & 25.25 & 22.58 & -2.67 & RBMC & \begin{tabular}{|l|}
7.95 \\
\end{tabular} & 12.95 & 5.00 & 19.34 & 23.62 & 4.28 \\
\hline REDD & -0.86 & 5.24 & 6.10 & 25.04 & 21.92 & -3.12 & REMB & \begin{tabular}{|l|}
0.31 \\
\end{tabular} & 5.92 & 5.61 & 12.37 & 16.99 & 4.62 \\
\hline RBJE & -5.86 & \begin{tabular}{|l|}
2.62 \\
\end{tabular} & \begin{tabular}{|l|l|}
8.48 \\
\end{tabular} & \begin{tabular}{|l|}
21.10 \\
\end{tabular} & 19.63 & \begin{tabular}{|l|l|}
-1.47 \\
\end{tabular} & REMA & \begin{tabular}{|l|}
0.05 \\
\end{tabular} & 3.92 & 3.87 & \begin{tabular}{|l|l|}
11.80 \\
\end{tabular} & 15.10 & \begin{tabular}{|l|}
3.3 \\
\end{tabular} \\
\hline RBJQ-A & -2.83 & 4.26 & 7.09 & 26.01 & 22.78 & -3.23 & REDE & 12.56 & 14.85 & 2.29 & 22.82 & 23.90 & 1.08 \\
\hline RBJQ-B & -3.33 & \begin{tabular}{|l|l|}
4.12 \\
\end{tabular} & 7.45 & 24.90 & 21.41 & -3.49 & REFD & 2.18 & 7.91 & 5.73 & \begin{tabular}{|l|}
13.04 \\
\end{tabular} & 17.58 & 4.54 \\
\hline RBJP & -4.02 & 5.08 & 9.10 & \begin{tabular}{|l|}
22.19 \\
\end{tabular} & 21.17 & \begin{tabular}{|l|}
-1.02 \\
\end{tabular} & REEA-ÂA & \begin{tabular}{|l|}
18.94 \\
\end{tabular} & 20.95 & \begin{tabular}{|l|}
2.01 \\
\end{tabular} & 30.12 & 31.29 & 1.17 \\
\hline RENN & -2.82 & 5.01 & 7.83 & \begin{tabular}{|l|}
23.73 \\
\end{tabular} & 21.23 & \begin{tabular}{|l|}
-2.50 \\
\end{tabular} & RBFC & \begin{tabular}{|l|}
8.54 \\
\end{tabular} & 13.09 & \begin{tabular}{|l|l|} 
& \\
\end{tabular} & \begin{tabular}{|l|}
20.32 \\
\end{tabular} & 24.13 & 3.81 \\
\hline REJO & -4.72 & \begin{tabular}{|l|l|}
4.28 \\
\end{tabular} & 9.00 & 22.82 & 20.66 & -2.16 & \begin{tabular}{|l|} 
RBCS-B Box \\
\end{tabular} & 6.94 & 12.22 & 5.28 & 17.53 & 22.13 & \begin{tabular}{|l|}
4.6 \\
\end{tabular} \\
\hline RELA-A & 4.43 & 10.35 & 5.92 & 28.77 & 24.66 & -4.11 & $\begin{array}{l}\text { RBCS-B Box } \\
\end{array}$ & \begin{tabular}{|l|}
-2.56 \\
\end{tabular} & -0.67 & 1.89 & 3.90 & 6.46 & 2.56 \\
\hline RELA-B & 1.47 & 8.29 & 6.82 & 26.70 & 22.97 & $\mid-3.73$ & REEH & 12.94 & 11.4 & -1.54 & 25.61 & 23.15 & -2.46 \\
\hline RELB & 3.75 & 10.04 & 6.29 & \begin{tabular}{|l|}
29.54 \\
\end{tabular} & 25.68 & -3.86 & REEA-B & 18.09 & 19.17 & 1.08 & 29.39 & 29.80 & \begin{tabular}{|l|l|}
0.41 \\
\end{tabular} \\
\hline$\overline{\mathrm{RBLC}}$ & 2.19 & 8.62 & 6.43 & 26.34 & 21.9 & -4.44 & RBFA & 9.24 & 10.09 & 0.85 & 21.39 & 21.58 & 0.19 \\
\hline REID & 0.18 & 9.37 & 9.19 & 24.77 & 22.42 & -2.35 & REEF-Ä & 13.43 & 14.57 & \begin{tabular}{ll|}
1.14 \\
\end{tabular} & 26.93 & 26.16 & -0.77 \\
\hline REIG & 5.26 & 12.98 & 7.72 & 29.35 & 25.63 & -3.72 & REEF-B & 11.06 & 9.6 & -1.46 & \begin{tabular}{|l|}
24.50 \\
\end{tabular} & 21.61 & -2.89 \\
\hline REIH & 4.83 & 11.65 & 6.82 & 28.10 & 24.5 & -3.60 & REGB & 5.50 & 7.85 & 2.35 & 18.78 & 19.91 & 1.13 \\
\hline RBIF & 3.12 & \begin{tabular}{|l|}
9.21 \\
\end{tabular} & 6.09 & 26.62 & 22.75 & \begin{tabular}{|l|}
-3.87 \\
\end{tabular} & RBDB & 26.60 & 25.29 & \begin{tabular}{|c|}
-1.31 \\
\end{tabular} & \begin{tabular}{|l|}
35.11 \\
\end{tabular} & 36.08 & 0.97 \\
\hline RBIC & 2.51 & 8.65 & \begin{tabular}{|l|l|}
6.14 \\
\end{tabular} & 26.39 & 21.68 & $\mid-4.71$ & RBDA & \begin{tabular}{|l|}
18.89 \\
\end{tabular} & 20.18 & 1.29 & \begin{tabular}{|l|}
31.47 \\
\end{tabular} & 31.93 & 0.46 \\
\hline RBIB & -7.43 & 4.93 & 12.36 & \begin{tabular}{|l|}
21.47 \\
\end{tabular} & 19.95 & \begin{tabular}{|l|}
-1.52 \\
\end{tabular} & RECZ & \begin{tabular}{|l|}
12.42 \\
\end{tabular} & 18.5 & \begin{tabular}{|l|l|}
6.08 \\
\end{tabular} & 25.97 & 29.96 & 3.99 \\
\hline REFF & -8.15 & \begin{tabular}{|l|l|}
4.29 \\
\end{tabular} & 12.44 & 17.82 & 17.99 & 0.17 & REGC & 5.07 & 10.47 & 5.40 & 20.49 & 22.96 & 2.47 \\
\hline RBIA & 15.00 & & 20 & 21.00 & 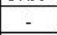 & & RBDC & 8.56 & 11.56 & 3.00 & 23.27 & 24.30 & 1.03 \\
\hline RBFE & -10.11 & -7.77 & \begin{tabular}{|l|l|}
2.34 \\
\end{tabular} & 13.50 & 10.93 & -2.57 & RBDG & 14.40 & 12.49 & \begin{tabular}{|l|}
-1.91 \\
\end{tabular} & 27.16 & 24.73 & -2.43 \\
\hline REKJ-C & -7.20 & -6.18 & 1.02 & \begin{tabular}{|l|}
19.41 \\
\end{tabular} & 16.18 & -3.23 & RBCI & 2.99 & 2.74 & -0.25 & 18.60 & 16.10 & \begin{tabular}{|l|l|} 
\\
\end{tabular} \\
\hline REKL-B & -6.86 & -6.62 & 0.24 & 21.54 & 16.76 & -4.78 & $\mathrm{RBCK}$ & 5.35 & 7.81 & 2.46 & 20.38 & 20.48 & \begin{tabular}{|l|}
0.1 \\
\end{tabular} \\
\hline RBKJ-Aू & -11.94 & -9.48 & 2.46 & \begin{tabular}{|l|}
14.78 \\
\end{tabular} & 17.14 & 2.36 & REFB-Ä & 7.55 & 7.94 & \begin{tabular}{|l|l|}
0.39 \\
\end{tabular} & 21.86 & 20.10 & -1.76 \\
\hline REKG & -4.26 & \begin{tabular}{|l|}
-4.19 \\
\end{tabular} & 0.07 & \begin{tabular}{|l|}
21.44 \\
\end{tabular} & 17.49 & -3.95 & $\mathrm{RECM}$ & \begin{tabular}{|l|}
7.84 \\
\end{tabular} & 10.04 & 2.20 & 22.12 & 22.70 & 0.58 \\
\hline$\overline{\text { REKE }}$ & -9.70 & -10.6 & \begin{tabular}{|c|}
-0.90 \\
\end{tabular} & \begin{tabular}{|l|}
17.40 \\
\end{tabular} & 16.87 & \begin{tabular}{|l|}
-0.53 \\
\end{tabular} & RECO & \begin{tabular}{|l|}
10.68 \\
\end{tabular} & 12.95 & 2.27 & 24.15 & 22.43 & -1.72 \\
\hline$\overline{R B K D}$ & -9.77 & \begin{tabular}{|l|l|}
-9.48 \\
\end{tabular} & 0.29 & 17.69 & 14 & -3.69 & REBA & \begin{tabular}{|l|}
4.47 \\
\end{tabular} & 5.44 & 0.97 & 16.36 & 16.24 & $\mid-0.12$ \\
\hline RBKH & -6.27 & -6.73 & -0.46 & 19.37 & 14.28 & -5.09 & $\mathrm{RBCW}$ & 18.73 & 25.94 & 7.21 & 33.90 & 36.45 & 2.55 \\
\hline REKB & -6.85 & -6.9 & -0.05 & \begin{tabular}{|l|}
20.09 \\
\end{tabular} & 15.38 & \begin{tabular}{|l|}
-4.71 \\
\end{tabular} & REGA & 2.96 & 11.02 & \begin{tabular}{|l|}
8.06 \\
\end{tabular} & 21.95 & 23.14 & 1.19 \\
\hline REKA & -7.32 & -8.09 & -0.77 & \begin{tabular}{|l|}
19.49 \\
\end{tabular} & 14.15 & -5.34 & RECY & 25.84 & $38.4 / 28.2 / 29.9$ & & 48.96 & 50.74 & 1.78 \\
\hline REKC-A & -11.06 & \begin{tabular}{|l|l|}
-8.14 \\
\end{tabular} & 2.92 & \begin{tabular}{|l|}
21.72 \\
\end{tabular} & 16.3 & \begin{tabular}{|l|l|}
5.42 \\
\end{tabular} & RECL-A & 8.64 & 13.7 & 5.06 & 19.40 & 22.04 & 2.64 \\
\hline REKC-B & -10.89 & -9.84 & 1.05 & 22.06 & 17.83 & -4.23 & RECL-B & 3.09 & 9.29 & 6.20 & 14.51 & 17.34 & 2.83 \\
\hline RBKC-C & -10.80 & -9.49 & 1.31 & 20.28 & 18.08 & -2.20 & RECL-C & 5.99 & 10.33 & \begin{tabular}{|l|l|}
4.34 \\
\end{tabular} & 20.43 & 22.22 & 1.79 \\
\hline RBFB-E & 4.59 & \begin{tabular}{|l|l|}
0.45 \\
\end{tabular} & \begin{tabular}{|l|}
-4.14 \\
\end{tabular} & \begin{tabular}{|l|}
27.86 \\
\end{tabular} & 20.16 & -7.70 & RECL-D & 11.61 & 10.48 & \begin{tabular}{|l|}
-1.13 \\
\end{tabular} & 22.55 & 22.31 & \begin{tabular}{|l|l|} 
& -0.24 \\
\end{tabular} \\
\hline RBFB-F & 2.53 & -2.46 & \begin{tabular}{|l|}
-4.99 \\
\end{tabular} & \begin{tabular}{|l|}
26.27 \\
\end{tabular} & \begin{tabular}{|l|}
18.31 \\
\end{tabular} & $\mid-7.96$ & RBDD-A $\mathrm{A}$ & 5.36 & 4.59 & \begin{tabular}{|l|}
-0.77 \\
\end{tabular} & 6.24 & 6.19 & -0.05 \\
\hline RBFB-D & -0.33 & & & 18.75 & & & RBDD-B & 5.37 & 3.9 & \begin{tabular}{|l|}
-1.47 \\
\end{tabular} & 6.24 & 5.97 & \begin{tabular}{|l|}
-0.27 \\
\end{tabular} \\
\hline REDH & 6.63 & \begin{tabular}{|l|}
4.63 \\
\end{tabular} & -2.00 & \begin{tabular}{|l|}
28.54 \\
\end{tabular} & 20.21 & -8.33 & RBDD-C & \begin{tabular}{|l|}
5.37 \\
\end{tabular} & 4.01 & \begin{tabular}{|l|}
-1.36 \\
\end{tabular} & 6.26 & 5.88 & \begin{tabular}{|c|} 
\\
\end{tabular} \\
\hline REDI & 5.95 & \begin{tabular}{|l|l|}
3.74 \\
\end{tabular} & \begin{tabular}{|l|}
-2.21 \\
\end{tabular} & \begin{tabular}{|l|}
28.51 \\
\end{tabular} & 17.88 & -10.63 & RBDD-D & \begin{tabular}{|l|}
5.37 \\
\end{tabular} & 3.87 & \begin{tabular}{|l|}
-1.50 \\
\end{tabular} & 6.25 & 5.99 & $\mid-0.26$ \\
\hline RBOB & 12.55 & \begin{tabular}{|l|}
7.1 \\
\end{tabular} & -5.45 & \begin{tabular}{|l|}
30.28 \\
\end{tabular} & 22.65 & -7.63 & & & & & & & \\
\hline RENB & 10.22 & 8.85 & \begin{tabular}{|l|}
-1.37 \\
\end{tabular} & \begin{tabular}{|l|}
31.70 \\
\end{tabular} & 22.51 & -9.19 & & & & & & & \\
\hline$\overline{R B N C}$ & 4.50 & 6.53 & \begin{tabular}{|l|}
2.03 \\
\end{tabular} & \begin{tabular}{|l|}
28.70 \\
\end{tabular} & 21.28 & \begin{tabular}{|l|}
-7.42 \\
\end{tabular} & & & & & & & \\
\hline RBHB & -2.57 & \begin{tabular}{|l|}
4.21 \\
\end{tabular} & \begin{tabular}{|l|l|}
6.78 \\
\end{tabular} & \begin{tabular}{|l|}
22.64 \\
\end{tabular} & 19.07 & \begin{tabular}{|l|}
-3.57 \\
\end{tabular} & & & & & & & \\
\hline RBHC & 0.53 & 6.06 & 5.53 & \begin{tabular}{|l|}
24.74 \\
\end{tabular} & 20.6 & -4.14 & & & & & & & \\
\hline RBSB & 6.79 & \begin{tabular}{|l|l|}
6.91 \\
\end{tabular} & \begin{tabular}{|l|l|}
0.12 \\
\end{tabular} & \begin{tabular}{|l|}
32.59 \\
\end{tabular} & 24.21 & -8.38 & & & & & & & \\
\hline RBSA & 15.00 & 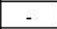 & & \begin{tabular}{|l|}
21.00 \\
\end{tabular} & & & & & & & & & \\
\hline RENA & 15.00 & - & & \begin{tabular}{|l|}
21.00 \\
\end{tabular} & & & & & & & & & \\
\hline REHE & 1.78 & \begin{tabular}{|l|}
8.31 \\
\end{tabular} & 6.53 & \begin{tabular}{|l|}
27.10 \\
\end{tabular} & 22.07 & \begin{tabular}{|l|}
-5.03 \\
\end{tabular} & & & & & & & \\
\hline RBFB-C & 7.85 & 13.36 & \begin{tabular}{|l|}
5.51 \\
\end{tabular} & \begin{tabular}{|l|}
30.48 \\
\end{tabular} & 26.45 & \begin{tabular}{|l|l|}
-4.03 \\
\end{tabular} & & & & & & & \\
\hline RBIE & 0.49 & 7.99 & \begin{tabular}{|l|}
7.50 \\
\end{tabular} & \begin{tabular}{|l|}
22.03 \\
\end{tabular} & 19.36 & \begin{tabular}{|l|}
-2.67 \\
\end{tabular} & & & & & & & \\
\hline REHD & -3.30 & \begin{tabular}{|l|}
3.71 \\
\end{tabular} & $\begin{array}{l}7.01 \\
\end{array}$ & 2027 & 1693 & 334 & & & & & & & \\
\hline RBDJ & 12.27 & 20.45 & 8.18 & \begin{tabular}{|l|}
34.17 \\
\end{tabular} & 33.19 & -0.98 & & & & & & & \\
\hline REDK & 13.13 & 22.21 & 9.08 & \begin{tabular}{|l|}
34.50 \\
\end{tabular} & & & & & & & & & \\
\hline REDL & 10.54 & 19.79 & 9.25 & \begin{tabular}{|l|}
34.13 \\
\end{tabular} & 33.37 & \begin{tabular}{|c|}
-0.76 \\
\end{tabular} & & & & & & & \\
\hline$\overline{\mathrm{RBOA}}$ & 17.94 & 23.16 & \begin{tabular}{|l|}
5.22 \\
\end{tabular} & \begin{tabular}{|l|}
37.02 \\
\end{tabular} & 34.32 & \begin{tabular}{|l|l|}
-2.70 \\
\end{tabular} & & & & & & & \\
\hline$\overline{\mathrm{RBHA}}$ & 15.00 & & & 21.00 & & & & & & & & & \\
\hline
\end{tabular}

than in Case 5. For PM, all the equipment temperatures are at the range of $16^{\circ} \mathrm{C}$ to $33^{\circ} \mathrm{C}$, except for the PIT equipment $\left(21^{\circ} \mathrm{C}\right.$ to $\left.43^{\circ} \mathrm{C}\right)$, MWT equipment $\left(15^{\circ} \mathrm{C}\right.$ to $\left.44^{\circ} \mathrm{C}\right)$ and equipment in PM20 $\left(34^{\circ} \mathrm{C}\right.$ to $\left.37^{\circ} \mathrm{C}\right)$. 
In Case 7, for Shunt, BDR and BCHC, the heat dissipation difference along the orbit is the same as the value used in Case 6. But the orbit average value of Case 7 is the same as Case 5 because the TM radiator areas were designed with heat dissipation of Case 5. According to the test results, all of the SM equipment were in the range of $14^{\circ} \mathrm{C}$ to $38^{\circ} \mathrm{C}$, except for the BAPTA that was at the level of $48.2^{\circ} \mathrm{C}$ to $49.1{ }^{\circ} \mathrm{C}$, this temperature is on the based on the old BAPTA heat dissipation of $20 \mathrm{~W}$ in sunlight and $20 \mathrm{~W}$ in eclipse to make contrast with Case 6 . The 4 Battery Pack temperatures were in the range of $4.5^{\circ} \mathrm{C}$ to $5.7^{\circ} \mathrm{C}$, the temperature difference of each pack was less than $0.4^{\circ} \mathrm{C}$. For PM, all the equipment temperatures were in the range of $24^{\circ} \mathrm{C}$ to $40^{\circ} \mathrm{C}$ except for the MWT equipment in the range of $20 \sim 42^{\circ} \mathrm{C}$ and

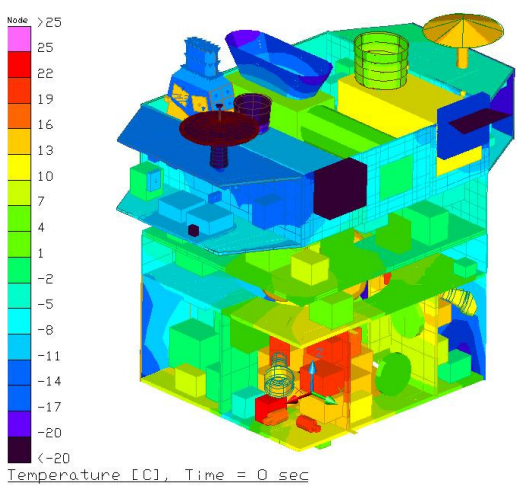

Figure 6. CBERS-3 TMM -INPE- 5000 nodes $\mathrm{PM} 20$ equipment in the range of $36^{\circ} \mathrm{C}$ to $38^{\circ} \mathrm{C}$.

Case 3, Phase $3 \mathrm{a}$ and Case 4 (to simulate the extreme cold steady-state case in the cold and hot emergency $\underline{\text { modes): }}$

In Case 3, all of the SM equipment were in the range of $4^{\circ} \mathrm{C}$ to $32^{\circ} \mathrm{C}$, except for the BAPTA that was in $41^{\circ} \mathrm{C}$. The 4 Battery Pack temperatures were in the range of $7.1^{\circ} \mathrm{C}$ to $7.6^{\circ} \mathrm{C}$ and the temperature difference of each pack was less than $0.5^{\circ} \mathrm{C}$. For PM, all the equipment temperature is at the range of $-2^{\circ} \mathrm{C}$ to $15^{\circ} \mathrm{C}$, except for $\mathrm{MWT}$ equipment $\left(-11^{\circ} \mathrm{C}\right.$ to $\left.0.8^{\circ} \mathrm{C}\right)$ and equipment in $\mathrm{PM}$ front panel $\left(21^{\circ} \mathrm{C}\right.$ to $\left.24^{\circ} \mathrm{C}\right)$.

In Phase $3 \mathrm{a}$, when all PM equipment were turned OFF, the SM equipment temperatures were almost the same as Case 3, but the PM equipment temperatures were much colder in relation to the Case 3 temperature results. All the equipment temperatures were at the range of $-19^{\circ} \mathrm{C}$ to $7^{\circ} \mathrm{C}$, except for the MWT equipment $\left(-17^{\circ} \mathrm{C}\right.$ to $\left.8^{\circ} \mathrm{C}\right)$ and equipment in $\mathrm{PM} 20\left(1.9^{\circ} \mathrm{C}\right.$ to $\left.10^{\circ} \mathrm{C}\right)$.

In Case 4 (hot safe mode) all the $\mathrm{SM}$ equipment were in the $11^{\circ} \mathrm{C}$ to $38^{\circ} \mathrm{C}$, except for the BAPTA that achieved $48^{\circ} \mathrm{C}$. The 4 Battery Packs temperatures were in the range of $12.4^{\circ} \mathrm{C}$ to $13.0^{\circ} \mathrm{C}$ and the temperature difference of each pack was less than $0.6^{\circ} \mathrm{C}$.

\section{Thermal mathematical models}

The satellite TMM developed by INPE with SINDA-FLUINT Thermal Desktop Software is composed of $\sim 5000$ nodes (Fig. 6). The TMM developed by CAST is composed of 2000 nodes (Fig. 7), and all the steps of the thermal analyses were done using in-house software. In the both mathematical models the density of finite elements numerical mesh over the structural panel was selected as a function of expected thermal gradients based on the proper experiences of each side. Special version of heat pipe sub-model was developed to represent two-channel versions of heat pipes embedded into panels, as well as for the Propulsion components. Both mathematic models were verified with test results. After the mathematic models are modified, the analysis for the emergency
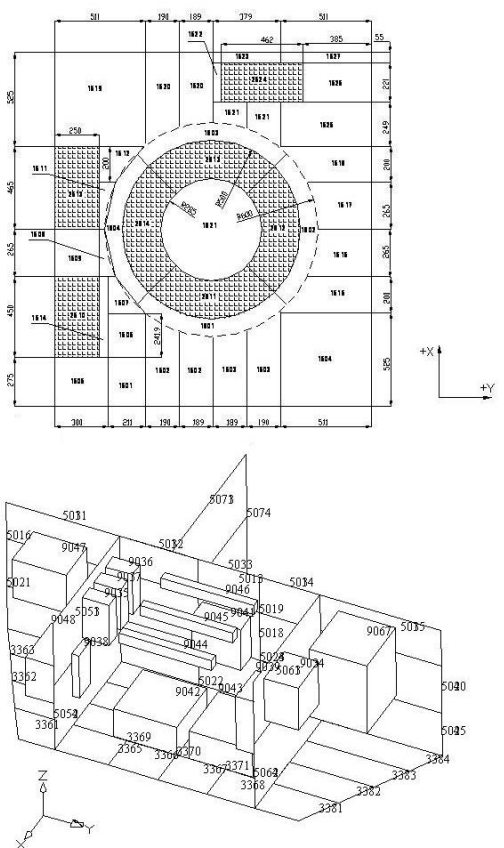

Figure 7. CBERS-3 TMM - CAST - 2000 nodes.

modes (cold and hot safe modes) was run with the new models and the results compared with test results.

\section{Correlation results}

The goal of the satellite TMM correlation efforts was to obtain equipment temperature predictions within $5^{\circ} \mathrm{C}$ from the values measured in the TBT. The first step in this process of correlating the TBT results with the mathematical prediction was to change the TMMs to the TM/TBT configuration. The Solar Array Generator panels were removed and all internal heat loads and imposed heat fluxes were reproduced. Separately, the sub-models of vacuum chamber and cold plates were added. 
Generally speaking the TMM parameters such as the contact thermal resistances, conductive couplings between panels, honeycomb panel effective conductances, equipment heat dissipations, SM and PM interface boundary conditions, etc. were adjusted by the test results. In addition to the numerical mesh parameters, such as mesh densities and type of elements (central or edge) were modified in order to fit better the measured data.

The Chinese TMM correlation results showed that for the total 49 equipment of SM, $89.8 \%$ of the temperature differences between test and simulation are less than $6^{\circ} \mathrm{C}$ (in this case $65.3 \%$ are less than $3^{\circ} \mathrm{C}$ ) in Cold Case 1 , and $98.4 \%$ are less than $6^{\circ} \mathrm{C}$ (being $88 \%$ less than $3^{\circ} \mathrm{C}$ ) in Hot Case 5. In both cases the temperature differences for all the other equipment are less than $8^{\circ} \mathrm{C}$ in cold condition and $6^{\circ} \mathrm{C}$ in the hot condition. For satellite PM the correlation results are also very nice being $89.8 \%$ of the temperature differences between test and simulation less than $6^{\circ} \mathrm{C}$ (in this case $65.3 \%$ are less than $3^{\circ} \mathrm{C}, 24.5 \%$ are less than $6^{\circ} \mathrm{C}$ and $10.2 \%$ less than $8^{\circ} \mathrm{C}$ ) in Cold Case 1 , and $100 \%$ are less than $6^{\circ} \mathrm{C}$ (being $88 \%$ less than $3^{\circ} \mathrm{C}$ and $12 \%$ less than $6^{\circ} \mathrm{C}$ ) in Hot Case 5 .

As the result of correlations of TMM developed by INPE the following figures were achieved for PM internal electronics equipment: average deviation is $-1.6 \mathrm{C}$; $95 \%$ of temperature differences between test and simulation are less than $8.9^{\circ} \mathrm{C}$. All temperature differences lie within the interval $-13^{\circ} \mathrm{C}$ to $+10.1^{\circ} \mathrm{C}$. For SM internal electronics equipment: average deviation is $-0.7^{\circ} \mathrm{C} ; 95 \%$ of temperature differences between test and simulation are less than $6.6^{\circ} \mathrm{C}$. All temperature differences lie within the interval $-9.8^{\circ} \mathrm{C}$ to $+5.5^{\circ} \mathrm{C}$.

\section{Lessons learned}

New hardware involved in the test, such as cold plates, radiometers, radiation arrays etc., should be tested, qualified and accepted by the thermal project system team in advance before the test begins, in order to have enough time to perform adjustment or reworks, if necessary and not jeopardize the specimen to be tested.

Radiometers used to measure the background heat fluxes are indispensable for TBT. If possible, each side of the satellite should have installed more than 2 radiometers in order to have more confidence and security in the heat fluxes measurements.

Data acquisition software should be user-friendly as much as possible in order to be possible to dump part of the test data during the test run and export it in some usual format like EXCEL without any additional efforts.

Cameras, which are insulated from the satellite and have its own internal thermal control, can be represented in the TMM by a very simplified geometry, but their baffles should be considered in more details. It is very desirable that the camera developer team delivers a simplified sub-model of the camera to the system team to integrate it into the satellite-level TMM.

The best way to have a successful TMM correlation is to begin with cold steady-state case, trying to adjust first the temperature of all panels at the points of thermocouple installations. The cold case conditions can reveal that even weak conductive couplings between panels make sensible effect on the equipment temperature and should be represented in the model. For the hot cases these weak couplings usually do not contribute to the overall heat balance, because internal radiative heat transfer becomes more significant.

\section{Conclusion}

CBERS-3\&4 TM TBT was done according to the specification. The test results are correct and show that the thermal design is in correct way for all cold and hot cases. Both models can be used for further project phases. The existence of two thermal mathematical models provides confidence on thermal project solutions and contributes to improve the quality of the thermal control and to solve current thermal issues. It can be considered as a new and promised practice in executing of thermal project in cooperation. Moreover, with the improvement on the TMM development confidence coming from the possibility of exchanging technical information and experience can drive the process of qualification of the thermal design to the analysis, reducing the schedule and cost of the project.

\section{References}

De Oliveira, F., Brasil - China - 20 anos de Cooperação Espacial: CBERS- O Satélite da Parceria Estratégica, Editora Cubo, 2009, São Carlos, SP

P. R. Martini. "Regional Cooperation through Space Technology: Basis for a South America Space Agency." Acta Astronautica, Vol. 51, No. 1-9, pp. 559-567, 2002

Sacchi, E., Costa, G., Poidomani, G. and Guglielmo, C. "An Overview of the Thermal Verification and Testing of Integral and Artemis Satellites". Proceeding of 30th ICES Conference, 2000, pp. 1-7.

S. J. Krein and N. M. Teti, "EO-1 Spacecraft Thermal Vacuum Testing: An Innovative Approach to Cost Effective Verification". Proceeding of 30th ICES Conference, 2000, pp. 1-14. 